\title{
El hecho y el hechizo juntos en la crónica
}

Froilán Escobar ${ }^{1}$

Recibido en 25 de noviembre de 2016, aceptado en 31 de marzo de 2017

\begin{abstract}
“Aunque los Estados Unidos han reivindicado para sí la invención o
el descubrimiento del periodismo literario, de las factions o de las «novelas de la vida real», como suelen denominarse allí los escritos de

Truman Capote, Norman Mailer y Joan Didion, es en América Latina donde nació el género y donde alcanzó su genuina grandeza." Tomás Eloy Martínez, "Defensa de la utopía” 2

"Las crónicas modernistas son los antecedentes directos de lo que en los años cincuenta y sesenta del siglo XX habría de llamarse 'nuevo periodismo' y 'literatura de no ficción " " Susana Rotker, La invención de la crónica ${ }^{3}$
\end{abstract}

\begin{abstract}
Resumen
El texto en cuestión, busca fundamentar que El nuevo periodismo, etiquetado así por Tom Wolfe en 1973, a partir de la traducción del título de su libro The New Journalism, de la editorial EW Johnson y reeditado después en español por la Editorial Anagrama, no surgió en Estados Unidos como muchos creen, sino en Latinoamérica, con el grupo de poetas modernistas (Rubén Darío, José Martí, Manuel Gutiérrez Nájera y otros,) los cuales, con sus crónicas, dieron inicio a este discurso periodístico a finales del siglo XIX.

\section{Palabras clave}

Nuevo Periodismo, New Journalism, poesía modernista, Rubén Darío, José Martí, Gutiérrez Nájera, discurso periodístico.
\end{abstract}

1. Licenciado en Periodismo y Máster en Comunicación Política. froilanescobar@gmail.com 2. "Defensa de la utopía". Conferencia ofrecida en el taller seminario "Situaciones de crisis en medios impresos", dictado en Santa Fe de Bogotá, Colombia, el 15 de marzo de 1996, en la Fundación para el Nuevo Periodismo Iberoamericano.

3. Rotker, Susana. La invención de la crónica. Fondo de Cultura Económica, México, 2005. pp. 16 y 230.

ISSN 1994-733X, Editorial Universidad Don Bosco, año 15, No.31, Junio-Diciembre de 2017, p.27-34 


\begin{abstract}
The text in question seeks to substantiate that the New Journalism, tagged by Tom Wolfe in 1973, after the translation of the title of his book The New Journalism, published by E.W. Johnson and later reissued in Spanish by Editorial Anagrama, did not emerge in the United States as many believe, but in Latin America, with the group of modernist poets (Rubén Darío, José Martí, Manuel Gutiérrez Nájera and others) who, with their chronicles, started this journalistic discourse in the late nineteenth century.
\end{abstract}

\title{
Keywords
}

New Journalism, New Journalism, modernist poetry, Rubén Darío, José Martí, Gutiérrez Nájera, journalistic discourse.

Los que por primera vez cometieron la herejía de juntar, en sorpresivo juego de contrarios, lenguaje referencial, propio del periodismo, con el lenguaje literario -no para producir una mezcla, como podría suponerse, sino para integrarlos armónicamente en una nueva construcción que les permitiera comprender y hacer que otros comprendieran los acontecimientos noticiosos en que todos estaban inmersos-, eran poetas latinoamericanos que escribían como corresponsales para los principales periódicos latinoamericanos, norteamericanos y europeos de su tiempo.

Para Susana Rotker y Tomás Eloy Martínez, que han investigado el tema a fondo, no hay ningún resquicio de duda: Rubén Darío ${ }^{4}$, José Martín ${ }^{5}$, Manuel Gutiérrez Nájera $^{6}$, entre otros, fueron los creadores de esta nueva construcción, integradora de referencias disímiles, en la que desaparecían los límites entre los distintos géneros discursivos, para que alguien real contara una historia real como si fuera un cuento de ficción.

Acababa de nacer la crónica de lo que después sería llamado “nuevo periodismo".

Ahí asomaba, entera, del árbol, la copa. Pero las raíces de ese espacio de confluencias había que buscarlas más atrás. Remontarse a los siglos XVI y XVII, época en que los Cronistas de Indias, al narrar el encuentro entre lo español y lo americano (y la conquista y colonización después), alucinaban ante la desaforada confusión de lo real, lo deslumbrante, exuberante e inesperado; ante la desmesura de los mitos y de un paisaje que los contaminaba: Cristóbal Colón,

4. Félix Rubén García Sarmiento, Metapa (hoy Ciudad Darío), Nicaragua, 18 de enero de 1867-León, Nicaragua, 6 de febrero de 1916.

5. José Julián Martí Pérez, La Habana, Cuba, 28 de enero de 1953-Dos Ríos, antigua provincia de Oriente, Cuba, 19 de mayo de 1895.

6. Manuel Gutiérrez Nájera, Ciudad de México, 22 de diciembre de 1858-Ciudad de México, 3 de febrero de 1895. 
Hernán Cortés, Bartolomé de las Casas, Toribio Benavente (Motolinía), Francisco López de Gómara, Álvar Nuñez Cabeza de Vaca, Bernal Díaz del Castillo, Fray Bernardino de Sahagún, el Inca Garcilaso de la Vega, Gonzalo Fernández de Oviedo, Pedro Cieza de León y tantos otros. Aquella insólita realidad, habitada por seres inéditos, dueños de culturas absolutamente diferentes, no tenía, todavía, para ellos, palabras que la nombraran. Y para colmo, al igual que más tarde los modernistas, tuvieron que mirar con nuevos ojos lo que ocurría en ese preciso instante en que ocurría. De ahí que trataran, en medio de la urgencia y el vértigo de esa inmediatez, de entender toda esa pluralidad a través de las imágenes europeas. De ahí también que lo mezclaran todo: la información de lo que tocaban, olían y comían, con lo que se les antojaba sobrenatural o monstruoso, con sus creencias míticas en sirenas, cíclopes, pigmeos, faunos y cinocéfalos que aparecían en el imaginario medieval, o con lo que escuchaban, veían y soñaban mientras eran tragados, junto con la realidad, por descomunales selvas o la luz enceguecedora del trópico. Era un mundo que nacía a medida que ellos lo iban escribiendo. Narrar era entonces un acto de fe, fervor y delirio que presuponía, paradójicamente, la certeza.

Los fundadores del movimiento modernista - corriente literaria de los convulsos finales del siglo XIX y principios del XX-, fueron herederos de esa exaltada manera de traspasar los límites, que incorporaba en sus crónicas, como espacio de transgresión y transculturación, los ecos de Fray Luis de León y de Baudelaire, los recursos de la prosa francesa de la época (especialmente de las chroniques publicadas en 1850 en el periódico Le Figaro) y la experiencia del parnasianismo, el impresionismo, el simbolismo, el expresionismo y, por supuesto, del propio periodismo que, mediante la crónica, como ejercicio de cotidiana temporalidad, abría la puerta para que entrara la vida. Todo confluía, pero como herencia no como imitación o repetición de moldes: a partir de una voluntad expresiva vital e innovadora que se constituía en un nuevo modo de decir.

Ellos, además, con su empecinada vocación latinoamericanista y fundacional de pensar y ver el mundo desde este lado del mundo (de "pensar en americano", diría Miguel de Unamuno), fueron los culpables de que las simbólicas y domesticadas cigüeñas, las legendarias portadoras de bebés -que por aquel entonces solo llegaban de París-, llegaran también de Managua, Buenos Aires, Ciudad de México, La Habana o de cualquier otra parte del continente.

Al revolucionar la poesía, revolucionaron también la cultura hispanoamericana, y por consiguiente su apasionado trabajo como cronistas, pues, en esencia, fueron la expresión de un profundo cambio histórico. El poeta y el periodista se fundieron, se volvieron uno solo, al tiempo que desafiaban, el uno y el otro, el canon recibido. Las características propias de su poesía - “la búsqueda de lo insólito, los acercamientos bruscos de elementos disímiles, la renovación permanente, las audacias temáticas, el registro de los matices, la mezcla 
de sensaciones...", según el crítico Ángel Rama en su libro Rubén Darío y el modernismo- eran también el fundamento de su experiencia periodística.

Se despojaban así del prejuicio de que la crónica como escritura de la inmediatez y lo fugaz era un género menor (excluido por la crítica literaria) y por el abordaje de temas y problemas considerados marginales por la cultura dominante (excluidos por los medios de prensa), carecía de trascendencia estética y de interés para la opinión pública, por tanto, era algo que no perduraría. Es decir, era todo un acto transgresor, no solo porque rescataban la memoria perdida, borrada, sino que se atrevían a instaurar lo efímero del presente con el lenguaje de lo eterno.

Desaparecían las rupturas de arte y no arte entre uno y otro quehacer. De la economía informativa, propia del discurso noticioso, se pasaba a una forma comunicativa que traducía expresivamente el idioma de la realidad humana -que habla por medio de acontecimientos-, a los inusitados acentos de los poetas modernistas.

Para Martí (según exponía ya en 1882, en el prólogo a "El poema del Niágara" de Juan Antonio Pérez Bonalde), la aparición de las crónicas en los periódicos significó la "descentralización de la inteligencia”, pues permitía llegar a un público mucho más amplio que el relacionado con el mercado de los libros, limitado sólo a una élite. Por tanto, el hecho en fue todo un salto democrático de la cultura.

A los recursos narrativos propios de la crónica, fruto del cruce incestuoso entre historia y literatura - puesto que según el ensayista mexicano Alfonso Reyes, "historia y literatura se mecieron juntas en la cuna de la mitología, y ésta no acierta a distinguir -ni le importa- el hecho del hechizo"7 -, sumaron entonces los del periodismo. La inmediatez del hecho real era contado con las técnicas de la novela. Un verdadero oxímoron, porque la novela remite a lo ficticio, a lo "inventado", mientras que el periodismo remite a la realidad inmediata, demostrable, comprobable. Es decir, para lograr esta nueva síntesis genérica, se violentó la estructura clásica informativa con la introducción de historias de personajes, diálogos, comentarios, analogías, juegos de oposiciones, saltos cronológicos, suspenso, visiones múltiples, proposiciones yuxtapuestas, metáforas y otras figuras literarias que, sin desvirtuar el suceso referencial, permitían la intensificación de la emoción con el fin primordial de conmover al lector.

Los acontecimientos cotidianos de una cambiante modernidad que avanzaba lentamente, dentro de la estructura patrialcal criolla, hacia el inicio de la industrialización capitalista, eran dados a conocer mediante un discurso en el 
que irrumpía - fluido, suelto, libre, complejo o incluso desproporcionado por la exaltación de la autenticidad y el individualismo extremo de la época-, el yo creador del periodista para narrar historias de un presente que, al decir de Ramón de Valle-Inclán, aún no era historia ${ }^{8}$ - porque historia y presente son palabras contradictorias por definición-, pero mediante un cronista atento a su entorno, se podía alcanzar "una verdad humana más profunda que los inventarios y calendarios históricos" y por ende, más realista que cualquier relato del pasado. Ese era el secreto donde poesía y vida se resolvían. Esta era la clave para alcanzar, a un tiempo, veracidad - puesto que el cronista que relataba había estado allí, había vivido, como testigo, lo que sucedió y como tal era la fuente primaria del hecho-; y autenticidad - puesto que creía firmemente que narrar la fugitiva realidad era la mejor forma de entenderla-, en una época que se debatía entre el escepticismo y el deslumbramiento tecnológico.

El acto fundacional quedó registrado con claridad. Para Martí, la crónica (la nueva épica, como él la llamaba), portadora de temas "culminantes y durables, y de valor humano", era la novela de la historia. Gutiérrez Nájera comprendió que "el cruzamiento en literatura" reivindicaba la condición o la manera de narrar la inmediatez periodística. Darío veía este cruce exaltado como algo natural, porque, decía: “Hoy, y siempre, un periodista y un escritor se han de confundir".

La crónica con su carga crítica y humana, que rompía convenciones y estereotipos, corrió afiebradamente por las galeras de los periódicos. Darío hacía sus despachos desde España, París, Roma, Londres y Berlín para La Nación de Buenos Aires y otros diarios argentinos como La Tribuna y El Tiempo, así como para El Mercurio de Valparaíso, Chile y La Prensa Libre de Costa Rica; Gutiérrez Nájera, por su parte, lo hacía en México para El correo Germánico, El Nacional, El Federalista, La Libertad, El Renacimiento; Martí, desde Estados Unidos, para La Opinión Nacional de Caracas, La Nación de Buenos Aires, El Partido Liberal de México, La Opinión Pública de Montevideo, La República de Honduras, La América de Nueva York, New York Herald, The Hour y The Sun.

Crónicas antológicas salieron de sus plumas en aquellos días en que, aun cuando todavía corría aletargado el siglo XIX, ya ellos adelantaban, pujante, a nivel de la palabra, el XX. El nuevo modo de decir entrañaba nuevas formas de percepción. Todos los temas cotidianos, desde el más pequeño, prosaico y marginal hasta los de mayor trascendencia y repercusión, eran susceptibles de ser tratados desde esta nueva manera de narrar y comprender el mundo: una pelea de boxeo; un funeral chino; una operación de la bolsa; una campaña electoral; el caso de una famosa y linda bailarina del Teatro Nacional de México que colgaba sus zapatillas

8. Cit. por Toño Angulo Daneri en "La importancia de estar allí. Del costumbrismo a la historia del presente: los desafíos del periodismo narrativo en el Perú”

9. Reyes, Alfonso. Obra cit. p. 108. 
para casarse; las contradicciones humanas que acarreaba el desplazamiento de las luces del gas por la deslumbradora luz eléctrica; el eclipse de sol del 18 de julio de 1860, que acaparó la tención del mundo y dio cita en España -uno de los países agraciados para poder contemplarlo en toda su magnitud- a reyes, periodistas y científicos; los días de año nuevo en contraposición con la miseria que vivían los pobres; los desastres producidos por terremoto de Charleston, o el proceso y ejecución de los siete obreros anarquistas de Chicago, etc., etc.

A esta nueva manera de hacer y de injertar en nuestras crónicas el mundo; a estas figuras fundadoras que pusieron delante de la palabra un camino ("el camino poético" que, como diría Susana Rotker, "comenzó en los periódicos y fue allí donde algunos modernistas consolidaron lo mejor de su obra"10), se sumaría el poeta guatemalteco Enrique Gómez Carrillo ${ }^{11}$. Tenía 17 años cuando empezó a colaborar en El Correo de la Tarde de Guatemala, dirigido por Rubén Darío en 1890. Fue Darío quien hizo posible que el presidente de ese país, Manuel Lisandro Barillas, le otorgara una beca para estudiar en Europa. El influjo del autor de Azul lo acompañaría toda su vida. Colaboró en numerosas publicaciones de España, Francia e Hispanoamérica. En su estancia en Madrid lo haría para el periódico El liberal y las revistas Madrid cómico, La vida literaria, Blanco y negro, La ilustración española y americana y Revista crítica. En La Nación de Buenos Aires publicó las crónicas de sus viajes por Rusia, India, China, Japón, el norte de África, Grecia y Jerusalén. Más tarde, al estallar la Primera Guerra Mundial en 1914, fue nombrado corresponsal de ese periódico para cubrir el frente de batalla en diferentes países. Fue uno de los modernistas más prolíficos. Al final de su vida tenía publicadas más de tres mil crónicas.

Gómez Carrillo tampoco establecía separación entre crónica y poesía. Sólo que para él había un distingo: «El arte, que en poesía es tan anticuado cual el mundo, en prosa es una conquista reciente». Es decir, asumía que lo nuevo de la escritura modernista era fruto del quehacer periodístico, más que del verso. De ahí que insistiera en su preocupación: «Labrar la frase lo mismo que se labra el metal, darle ritmo como a una estrofa, retorcerla ni más ni menos que un encaje». Los cánones formales propios de poesía eran traspasados a la prosa, con lo cual se hacía patente el encuentro en la crónica de las dos modalidades expresivas: «os juro que ningún abuelo lo hizo.»12, decía.

No obstante, Gómez Carrillo es uno de los últimos barcos que zarpa del puerto de la llamada Belle Époque, que daba paso, con el nuevo siglo, a la globalización de la guerra y a la vanguardia literaria, período en que la modernización y la cruda transición social, se reflejarían en la crónica, aunque no necesariamente

10. Rotker, Susana:Ob. Cit., p. 108.

11. Enrique Gómez Tible (más conocido por Enrique Gómez Carrillo), Ciudad de Guatemala, 27 de febrero de 1873- París, 29 de noviembre de 1927.

12. Gómez carrillo, Enrique. El arte de trabajar la prosa artística (1905). Cit. por Harold Alvarado. 
llegaron a suponer -como apuntaran José Olivio Jiménez y Antonio R. de la Campa (1976) - el final del modernismo.

La vieja herencia de entender la dura la realidad representándola, se renovaba transgresoramente con este modo de atestiguar los hechos desde el cruce de las contradicciones de una modernidad que se debatía entre la duda y la fe en el futuro, el yo y lo colectivo, el anuncio del peligro del imperialismo y el canto a los Estados Unidos como modelo del progreso, los ideales de libertad en el trabajo periodístico y las presiones que se ejercían en la prensa para limitar los juicios, la búsqueda de lo autóctono y la idealización de España, la necesidad de abordar y pensar lo cotidiano y el deseo irrefrenable de lo universal.

Este fue el comienzo de la genuina expresión americana. Nacía así, a bordo de esta nueva construcción, con un lenguaje original, exaltado y deslumbrante, que conformaba un espacio de condensación y ebullición más amplio, donde desaparecían las fronteras entre distintos géneros discursivos, que terminaba - como decía Lezama en el caso de Martí- por reformar la realidad.

Es cierto: fue algo insólito. El nuevo género era capaz de producir taquicardia entre los que aun hoy, por estar acostumbrados a ver el mundo en términos de verdad/falsedad (en referencia al periodismo y a la literatura), pregonan que la inapresable y laberíntica realidad -que no sabe ser de una sola manera y a veces incluso resulta inverosímil-, tiene la obligación de ser objetiva cuando se convierte en lenguaje.

Los modernistas, en el afán de universalización y búsqueda de lo autóctono, llevaron la crónica más allá de sus límites. Transgredieron fronteras, paladearon con vehemencia las palabras y crearon, como dice el periodista mexicano Juan Villoro, esta especie de "ornitorrinco de la prosa", híbrido entre veracidad e imaginación, pero que al unir dos modalidades expresivas distintas, aparentemente separadas y enemistadas por viejas oposiciones que parecían irreconciliables, produjo un proverbial antídoto contra la amnesia social y una nueva manera de contar la experiencia humana. Se le dio así un vuelco al modo de representar la realidad, no a partir del acontecimiento como lo más importante (que reduce a los protagonistas a simple referencias textuales), sino a partir de los protagonistas, es decir, de lo que le ocurría a alguien en alguna parte de este vasto territorio latinoamericano. 


\section{Bibliografía}

Alvarado Tenorio, Harold. Enrique Gómez Carrillo y el Modernismo. www.arquitrave. com.

Escobar, Froilán. Defensa de la utopía, Conferencia ofrecida en el taller seminario 'Situaciones de crisis en medios impresos'. Fundación para el Nuevo Periodismo Iberoamericano, Santa Fe de Bogotá, Colombia, 15.03.1996.

García Sarmiento, Félix Rubén, Metapa (hoy Ciudad Darío), Nicaragua, 18.01.1867-León, Nicaragua, 06.02.1916.

Gutiérrez Nájera, Manuel, Ciudad de México, 22.12.1858-Ciudad de México, 03.02.1895. Martí Pérez, José Julián, La Habana, Cuba, 28.01.1953, Dos Ríos, antigua provincia de Oriente, Cuba, 19 de mayo de 1895.

Reyes, Alfonso. El deslinde / / Apuntes para una teoría de la literatura. Obras Completas XV. F.C.E. México, 1997.

Rotker, Susana. La invención de la crónica. Fondo de Cultura Económica, México, 2005. 